THE WORKING AND MAINTENANCE OF STEAM BOILERS.

$\mathrm{I}$ these days of high-priced coal, the memorandum which has recently been issued by Mr. C. E. Stromeyer, chief engineer of the Manchester Steam Users' Association, will be read with much interest by engineers and boiler owners. The coal bill for a Lancashire boiler amounts to from $300 l$. to $600 l$. per annum, and careless stoking may easily increase this cost in a very large proportion. Lack of proper attention to minor defects, which should be remedied as soon as detected, may also greatly increase the coal bill and shorten the life of the boiler. The memorandum covers a very wide field, such as economiser defects, external and internal corrosion, leakage, etc. Of special interest are Mr. Stromeyer's remarks regarding mechanical stokers.

Experience indicates that mechanical stokers, which naturally aim at improved efficiency and therefore high furnace temperatures, require not only that they should be carefully looked after and kept in good repair, but also that the boiler should receive far more care and attention than are necessary with hand-firing. Scale, and to a certain extent grease, may be tolerated in hand-fired boilers, but every effort should be made to remove these injurious substances if increased economy is aimed at by the adoption of mechanical stokers. Mr. Stromeyer gives some illustrations of the increased liability to damage due to increase in the temperature of the furnace. The boilers of a large steamer had been giving no trouble until an improved fire-grate was fitted. A saving of about Io per cent. in the coal bill resulted, but during the next voyage all the eighteen furnaces gradually bulged, in spite of a reduction of speed and power. The bulging could have been stopped if the improvement due to the new grate had been nullified either by keeping the furnace doors open and admitting an excess of cold air, or by closing all airholes in the doors, restricting the air admission but spoiling the efficiency.

Mechanical stokers designed to burn anthracite will almost certainly fail if fed with coking coal, and vice versa. It is not nossible to design a mechanical stoker which shall be satisfactory with all classes of coal.

From an economical point of view it is more important to keep the boiler heating surfaces free from soot and tarry matter than to remove the scale from the interior surfaces; the wear and tear question, however, demands that the inside of a boiler should be kept clean. Scale and grease hinder the heat which enters the plate from passing into the water. The radiating power of incandescent fuels, or flames, increases as the fourth power of the temperature, hence boilers which have worked satisfactorily, but inefficiently, with a comparatively low furnace temperature, even though the plates may be covered with scale or grease, are likely to give trouble if the furnace temperature, and with it the efficiencv, are increased. It is not strictly true to say that scale and grease reduce the efficiency of a boiler; they merely make it unprofitable to adopt an efficient system of combustion.

Slow bulging of the furnaces may be caused by the deposition of scales of crystals from any boiler water containing more than 4 per cent. of soluble salts. It is more than probable that plates which on one side are exposed to an intense heat, are on the other side covered chiefly with bubbles and sprays of burst bubbles, which leave their dissolved salt on the boiler plate while the water is evaporated. If the intense heat and rapid evaporation can be maintained locally, and this seems to be the case if mechanical stokers are worked very hard, crusts of salt will form here and there on the heating surface. Sometimes they will be washed away with a slight change of evaporation or circulation, but sometimes they will remain attached to the plates for a sufficiently long period to cause overheating. Drops of water which fall on hot plates are in a spheroidal condition, do not wet the plate, and consequently will not dissolve any salt scale which has formed there. As soon as a little bulging has been effected, the salt crusts will doubtless break off, but as bulges are exposed to the flames more than other parts, salt crusts are likely to reform in them, and gradually the bulge grows larger and larger until it is detected. As soon as the fire is drawn the salt crusts are dissolved away, and the bulges are said to be due to mysterious causes. 'This danger is naturally greatest with boilers having a bad circulation.

\section{BEHAVIOUR OF PLANTS IN RESPONSE TO THE LIGHT. 1}

I $\mathrm{N}$ the whole realm of biological science there is perhaps no phenomenon of greater fundamental importance than that exhibited by green plants in the transformation of carbon dioxide and water into starch and sugar. That this can only take place through the action of light upon chlorophyll is commonplace knowledge, but exactly how it is effected we do not know. Of the light that falls upon a green leaf a part is reflected from its surface, a part is transmitted, and another part is absorbed. That which is reflected and transmitted gives to the leaf its green colour; that which is absorbed, consisting of certain red, blue, and violet rays, is the source of the energy by means of which the leaf is enabled to carry on its work.

The extraordinary molecular complexity of chlorophyll has recently been made clear to us by the researches of Willstätter and his pupils; Usher and Priestley and others have shown us something of what takes place in chlorophyll when light acts upon it; and we are now beginning to realise more fully what a very complex photo-sensitive system the chlorophyll must be, and how much has yet to be accomplished before we can picture to our minds with any degree of certainty the changes that take place when light is absorbed by it. But the evidence afforded by the action of light upon other organic compounds, especially those which, like chlorophyll, are fluorescent, and the conclusion according to modern physics teaching that we may regard it as practically certain that the first stage in any photo-chemical reaction consists in the separation, either partial or complete, of negative electrons under the influence of light, leads us to conjecture that, when absorbed by chlorophyll, the energy of the light-waves becomes transformed into the energy of electrified particles, and that this initiates a whole train of chemical reactions resulting in the building up of the complex organic molecules which are the ultimate products of the plant's activity.

The absorption of light by the leaf is therefore of great physiological importance, and we have only to look at any of the plants around us to see how successfully they contrive to arrange their leaves to obtain the maximum advantage from the light that falls upon them. A plant organ responds to the directive influence of light by a curvature which places it either in a direct line with the rays of light as in grass seedlings, or at right angles to the light as in ordinary foliage leaves.

1 Evening discourse delivered before the British Assuciation at Manchester on September 9, by Dr. Harold Wager, F.R.S.

No. 2408, VOL. 96] 